\title{
Structural transformations in Sc/Si multilayers irradiated by EUV lasers
}

\author{
Dmitriy L. Voronov*a, , Evgeniy N. Zubarev ${ }^{\mathrm{b}}$, Yuriy P. Pershyn ${ }^{\mathrm{b}}$, Victoriya A. Sevryukova ${ }^{\mathrm{b}}$, \\ Valeriy V. Kondratenko ${ }^{\mathrm{b}}$, Alexander V. Vinogradov ${ }^{\mathrm{c}}$, Igor A. Artioukov ${ }^{\mathrm{c}}$, Yuriy A. Uspenskiy ${ }^{\mathrm{c}}$, \\ Michael Grisham ${ }^{\text {d }}$, Georgiy Vaschenko ${ }^{d}$, Carmen S. Menoni ${ }^{\mathrm{d}}$, and Jorge J. Rocca ${ }^{\mathrm{d}}$ \\ ${ }^{a}$ Lawrence Berkeley National Laboratory, Berkeley, California, 94720 \\ "National Technical University "KhPI", Kharkov, Ukraine \\ ${ }^{c}$ P. N. Lebedev Physical Institute, Moscow 117942, Russia \\ ${ }^{\mathrm{d}}$ Colorado State University, Fort Collins, Colorado, 80523
}

\begin{abstract}
Multilayer mirrors for the extreme ultraviolet (EUV) are key elements for numerous applications of coherent EUV sources such as new tabletop lasers and free-electron lasers. However the field of applications is limited by the radiation and thermal stability of the multilayers. Taking into account the growing power of EUV sources the stability of the optics becomes crucial. To overcome this problem it is necessary to study the degradation of multilayers and try to increase their temporal and thermal stability. In this paper we report the results of detailed study of structural changes in $\mathrm{Sc} / \mathrm{Si}$ multilayers when exposed to intense EUV laser pulses. Various types of surface damage such as melting, boiling, shock wave creation and ablation were observed as irradiation fluencies increase. Cross-sectional TEM study revealed that the layer structure was completely destroyed in the upper part of multilayer, but still survived below. The layers adjacent to the substrate remained intact even through the multilayer surface melted down, though the structure of the layers beneath the molten zone was noticeably changed. The layer structure in this thermally affected zone is similar to that of isothermally annealed samples. All stages of scandium silicide formation such as interdiffusion, solid-state amorphization, silicide crystallization etc., are present in the thermally affected zone. It indicates a thermal nature of the damage mechanism. The tungsten diffusion barriers were applied to the scandium/silicon interfaces. It was shown that the barriers inhibited interdiffusion and increased the thermal stability of $\mathrm{Sc} / \mathrm{Si}$ mirrors.
\end{abstract}

Keywords: capillary-discharge EUV laser, Sc/Si multilayer EUV optics, laser ablation, silicide formation, diffusion barriers

\section{INTRODUCTION}

Multilayer x-ray mirrors (MXMs) consisting of alternating films of two or more materials are of high efficiency in the wavelength range from hard x-rays $(\lambda \sim 0.1 \mathrm{~nm})$ to EUV $(\sim 60 \mathrm{~nm}) .{ }^{1}$ They are widely used in optical systems applied in astrophysics, ${ }^{2-4}$ x-ray lithography, ${ }^{5-7}$ x-ray microscopy (including both water $^{8-11}$ and carbon ${ }^{12,13}$ windows), microanalysis, ${ }^{14-16}$ and many other fields of science and technology. Requirements of a high reflectivity for such multilayers (MLs) as a rule define a specific material pair for construction. That is why in most cases MXMs represent a non-equilibrium layered system that can degrade even with moderate external perturbation: heating, irradiation, deformation, chemical reaction with environment etc.

Today new powerful sources of X-EUV rays (free electron lasers, ${ }^{17-19}$ synchrotrons,${ }^{20}$ discharge capillary lasers, ${ }^{21,22}$ and others) as well as laser cavities, ${ }^{23}$ and laser plasmas deliver pulsed X-EUV radiation of extremely high intensity and fluence. Exposed to such radiant flux MXMs can degrade or be destroyed, that makes their application unpractical. Therefore there exists a necessity to determine extreme conditions of MXM applications and mechanisms of their degradation.

From the other hand the process of interacting X-EUV radiation with MLs can be of particular interest for surface processing of matter. ${ }^{24}$ Especially in the case of layered systems capable of forming compounds.

*DLVoronov@lbl.gov, tel.1-510-486-4863 
$\mathrm{Sc} / \mathrm{Si} \mathrm{MXMs}$ proved to be most effective material pair for the wavelength range of 38-50 $\mathrm{nm}$. They show their practical usefulness in such applications as laser interferometry, ${ }^{25}$ polarimetry, ${ }^{26}$ ellipsometry, ${ }^{27,28}$ reflectometry, ${ }^{27}$ spectroscopy, ${ }^{29}$ material ablation, ${ }^{28,30}$ plasma creation, ${ }^{28}$ and nano-scaled microscopy. ${ }^{31-33}$ The Sc/Si MXMs were specially designed and fabricated as optics for capillary-discharge lasers capable of providing the radiation at $\lambda=46.9 \mathrm{~nm}$ with fluences up to $100 \mathrm{~J} / \mathrm{cm}^{2}$ per pulse. ${ }^{30}$

We reported earlier about some results on the damage to Sc/Si MXMs under irradiation of laser pulses. ${ }^{34-35}$ In this work we address the interaction of X-ray laser radiation with MLs featuring structural, phase, and morphological modifications under conditions of different heat removal from the irradiated area, and different stress states. Previous results are summarized.

\section{EXPERIMENT}

Irradiation of Sc/Si MLs with EUV laser beams at $\lambda=46.9 \mathrm{~nm}$ were made on a setup described in ref. ${ }^{28} \mathrm{~A}_{\text {flat }}$ multilayer sample with an area of less than $30 \mathrm{~mm}^{2}$ was placed on a movable platform so that incident beam focused by the Sc/Si MXM on a spherical substrate fell almost at normal incidence to the sample surface. To change the fluence value we moved the sample through the focus with a stepping motor. The laser worked in a pulsed mode with a pulse frequency of $\sim 1 \mathrm{~Hz}$ and nanosecond $(\sim 1.2 \mathrm{~ns})$ pulse duration. The energy of one laser pulse was $\sim 0.13 \mathrm{~mJ}$.

The Sc/Si multilayer samples were deposited by DC magnetron sputtering onto float glass or Si-wafer substrates with an RMS roughness of 0.4-0.6 nm. Nominal period value and fraction of Sc-containing layer in the period were $\sim 27 \mathrm{~nm}$ and $\sim 0.5$ respectively. All Sc/Si MLs were terminated by silicon layer. Multilayer samples of specified parameters were capable to reflect EUV with wavelength of $46.9 \mathrm{~nm}$ at normal incidence. Preliminary measuring one of Sc/Si MXM reflectivities gave $30-35 \%(\lambda=46.9 \mathrm{~nm})$.

Surface morphology of the samples was studied with scanning electron microscope (SEM) JSM-820 and optical microscope Nikon Optiphot. Transmission electron microscope (TEM) images of layer and interface structure were obtained in the PEM-U microscope at an accelerated voltage of $100 \mathrm{kV}$ and resolution better than $0.3 \mathrm{~nm}$. The technique to prepare ML cross-sections was similar to that in ref. ${ }^{36}$ and was described earlier in ref. ${ }^{37}$

We prepared Sc/Si MLs with a different number of periods, namely $\mathrm{Sc} / \mathrm{Si} / 10, \mathrm{Sc} / \mathrm{Si} / 33$ and $\mathrm{Sc} / \mathrm{Si} / 47$. Separately for inplane TEM study we deposited three-layers $\mathrm{Si} / \mathrm{Sc} / \mathrm{Si}$ (or $\mathrm{Sc} / \mathrm{Si} / 1.5$ ) with layer thicknesses similar to those in ordinary MLs. Then three-layers were detached from the substrate using a standard technique, placed onto TEM grid and exposed to focused EUV rays in such a state.

\section{RESULTS AND DISCUSSION}

$\mathrm{Si} / \mathrm{Sc} / \mathrm{Si}$ three-layer samples $(\mathrm{Sc} / \mathrm{Si} / 1.5 \mathrm{MLs})$ on the TEM copper grid were irradiated by the laser beam at fluence of $\sim 0.1 \mathrm{~J} / \mathrm{cm}^{2}$. Three shots were made at such samples.

TEM images of the irradiated samples are shown in Fig. 1. A TEM grid with hexagonal cells of $160 \mu \mathrm{m}$ width is visible as a dark image (Fig. 1a). The layered sample being gray color has two holes of an oval form with torn edges. As the fluence value for this sample exceeds the melting threshold ${ }^{34}\left(0.08 \mathrm{~J} / \mathrm{cm}^{2}\right)$, the molten part most likely separated from the rest due to an action of surface tension force. We observed several evidences of melt button formation during ablation of MLs (see below). We studied the isthmus between two holes of 75-100 $\mu \mathrm{m}$ wide visible within one of the cells in Fig. 1b. The central part of the isthmus (indicated by arrow) $30-60 \mu \mathrm{m}$ wide has the structure similar to the initial one: amorphous silicon layers $(a-\mathrm{Si})$ and crystal scandium layer $(c-\mathrm{Sc})$ with grain dimension of $\sim 10 \mathrm{~nm}$. Within $\sim 20 \mu \mathrm{m}$ from the hole edges the tree-layer structure changes to a composite of crystal silicide $\mathrm{c}_{-} \mathrm{Sc}_{3} \mathrm{Si}_{5}$ and $a$-Si (Fig. 1b). Several microns further (on the right of Fig. 1b outside the field of vision) it transforms to a composite of c-Sc $\mathrm{Si}_{5}$ and $c$-Si and doesn't change till the very edge of the hole. Here the dimension of silicide grains is less than $\sim 170 \mathrm{~nm}$.

The distinguishing feature of three-layer samples is the absence of heat removal to the substrate (we neglect the extraction of heat through TEM grid). In other words, structural transformations taking place in the layered sample are the result of direct influence of EUV laser radiation. These visible changes correspond to different thermal loads and can be compared with results from isothermal annealings ${ }^{38,39}$ to estimate the temperature in structure-modified regions. In previous work $^{40}$ for annealed Sc/Si MLs we found that silicide $a$-ScSi is formed within a temperature range of 270-620 $\mathrm{K}, a-\mathrm{Sc}_{3} \mathrm{Si}_{5}$ can be formed at temperatures of 570-690 K, and above $690-700 \mathrm{Ka}-\mathrm{Sc}_{3} \mathrm{Si}_{5}$ silicide is crystallized. As for 
crystallization (transition from amorphous to crystalline state) it is not required for atoms to make long diffusion migrations. It is enough to have atomic-sized displacements, then crystallization of $a$-Sc $\mathrm{Si}_{5} \mathrm{indicates}_{5}$ a short-time rise in sample temperature above characteristic annealing temperature, i.e. higher $700 \mathrm{~K}$.
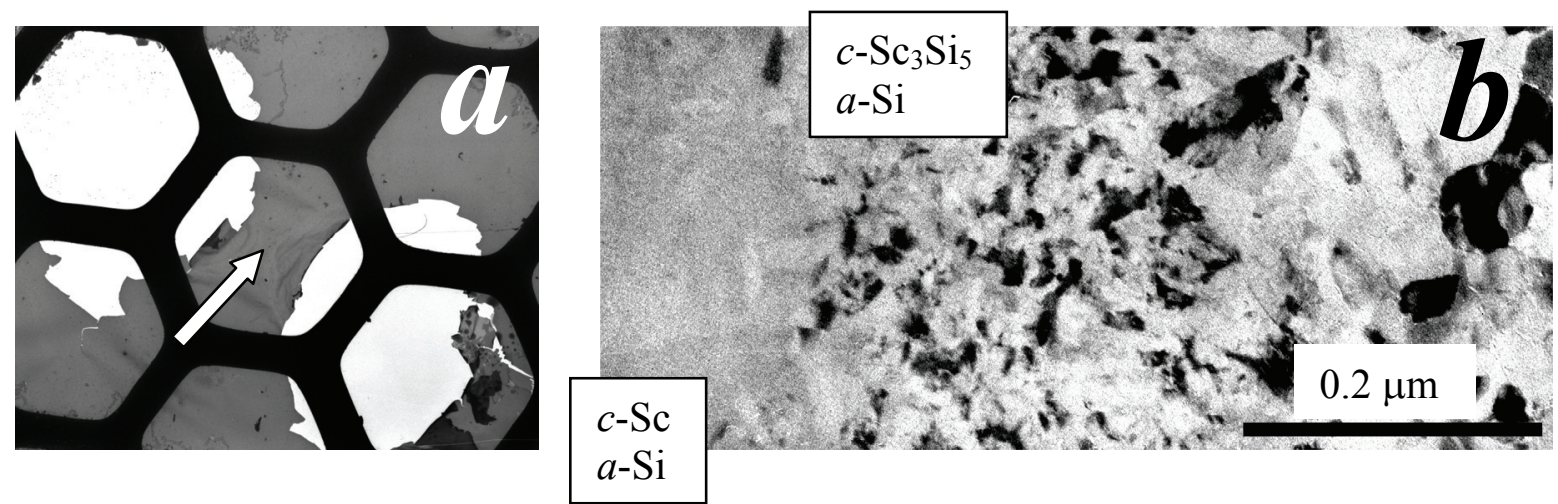

Fig. 1. TEM images after irradiation of Si/Sc/Si three-layer by 46.9 -nm laser with fluence of $\sim 0.1 \mathrm{~J} / \mathrm{cm}^{2}$. (a) Free-standing sample on the TEM grid with cell dimension of $160 \mu \mathrm{m}$. (b) TEM image of three-layer sample in the 20 - $\mu \mathrm{m}$ region from the hole edge showing the margin of the laser damage.

The change of structural state for Si-layers approaching the hole edge also points to a temperature gradient. It is known that crystallization of $a$-Si depends on annealing time and a contacting metal, and may occur in a wide temperature range of 450-1220 K. ${ }^{41-45}$ During thermal annealing of $\mathrm{MoSi}_{2} / \mathrm{Si}$ and $\mathrm{Sc} / \mathrm{Si}$ multilayers ${ }^{46,47}$ we also observed the crystallization of $a$-Si at temperatures of $\sim 1000 \mathrm{~K}$ and $\sim 970 \mathrm{~K}$, respectively. As it is a fast-running process we can expect that the temperature in the region of $\sim 18 \mu \mathrm{m}$ wide surrounding the holes $(c-\mathrm{Si}$ is present) reached at least $1000 \mathrm{~K}$, and in the adjoining region of several microns wide the temperature is $\sim 300$ degrees lower.

Melting of Sc/Si multilayer samples on substrates under laser pulse as was established by TEM methods necessarily results in the formation of $a-\mathrm{Sc}_{3} \mathrm{Si}_{5}$ in the sub-surface (this part of layered sample is absent in Fig. 1a). Also, the grain size of $c-\mathrm{Sc}_{3} \mathrm{Si}_{5}$ in this case is less than that observed in the samples without a substrate (Fig. 1b) and doesn't exceed 50 $\mathrm{nm}$. If the melting doesn't penetrate the entire multilayer to the substrate then as it was shown before ${ }^{34}$ a heat-affected zone (HAZ) is joined to the molten zone (MZ), and next to HAZ the virgin part of the sample survives. Figure 2 shows a region of $\mathrm{Sc} / \mathrm{Si} / 33 \mathrm{ML}$ in which only 11 periods remain after a laser shot with fluence of $\sim 0.13 \mathrm{~J} / \mathrm{cm}^{2}$. Three of them have modified period and composition and represent HAZ. Within this HAZ the structure of the multilayer changes drastically from silicide/Si (close to $\mathrm{MZ}$ ) to $\mathrm{Sc} / \mathrm{Si}$ with enlarged amorphous interfaces. The changes of structure and phase composition are similar to those observed at isothermal annealings ${ }^{38,39}$. As it can be calculated 22 of 33 periods are destroyed completely (on the left in Fig. 2).

Since Sc/Si MLs consist of layers having a high enthalpy of mixing for silicides (e.g. $-71 \mathrm{~kJ} / \mathrm{moll}$ for $\mathrm{Sc}_{3} \mathrm{Si}_{5}$ ), ${ }^{48}$ the heat released during reaction of Sc and $\mathrm{Si}$ facilitates the enhancement of thermal effects. We observed multiple (from 3 to 6 ) expansions of $\mathrm{MZ}$ in depth compared to expected $\mathrm{MZ}$ for fluences above the melting threshold. ${ }^{34,49}$ There was also a finding of partial ablation of multilayer material at fluences below any expected ablation. ${ }^{49}$ Our estimation predicts only 4 periods to be molten at the surface of Sc/Si/33 ML (Fig. 2) under direct laser irradiation. However we see 22 destroyed periods, that is $\sim 5$ times as many as expected.

Experimental consequences of irradiation can noticeably differ for MXMs with different number of periods. Thus, for example, in the case of the $\mathrm{Sc} / \mathrm{Si} / 1.5$ multilayer the melting under fluence of $\sim 0.1 \mathrm{~J} / \mathrm{cm}^{2}$ results in the physical detachment of the melt from the sample as shown above in Fig. 1a. For the $\mathrm{Sc} / \mathrm{Si} / 10$ multilayer the irradiation with fluence of $\sim 1.4 \mathrm{~J} / \mathrm{cm}^{2}$ causes an intense ablation (Fig. 3a). On the other hand similar fluence $\left(\sim 1.3 \mathrm{~J} / \mathrm{cm}^{2}\right)$ produces an ablation of only a small area ( $\sim 5 \%$ of the laser imprint area) in the $\mathrm{Sc} / \mathrm{Si} / 33$ multilayer. As the $\mathrm{Sc} / \mathrm{Si} / 10$ sample was deposited onto the float glass substrate having noticeably lower thermal conductivity $\left(\sim 1.6 \mathrm{~W} / \mathrm{m} / \mathrm{K}^{50}\right)$ compared to the Sc and $\mathrm{Si}$ ones $\left(\sim 16\right.$ and $\sim 117 \mathrm{~W} / \mathrm{m} / \mathrm{K}$, correspondingly $\left.{ }^{51}\right)$, conditions of the heat removal for this sample is similar to that for $\mathrm{Sc} / \mathrm{Si} / 1.5$ sample, i.e. along the multilayer body. Besides, these multilayers have a molten depth comparable with their thickness for the indicated fluences. Therefore released energy induced by both laser radiation absorption and 
chemical reaction accumulates mainly within the multilayer volume. In the case of the $\mathrm{Sc} / \mathrm{Si} / 33$ multilayer, the multilayer itself removes the part of heat from the molten region, so the damage scale in this case is much less (Fig. 3b).

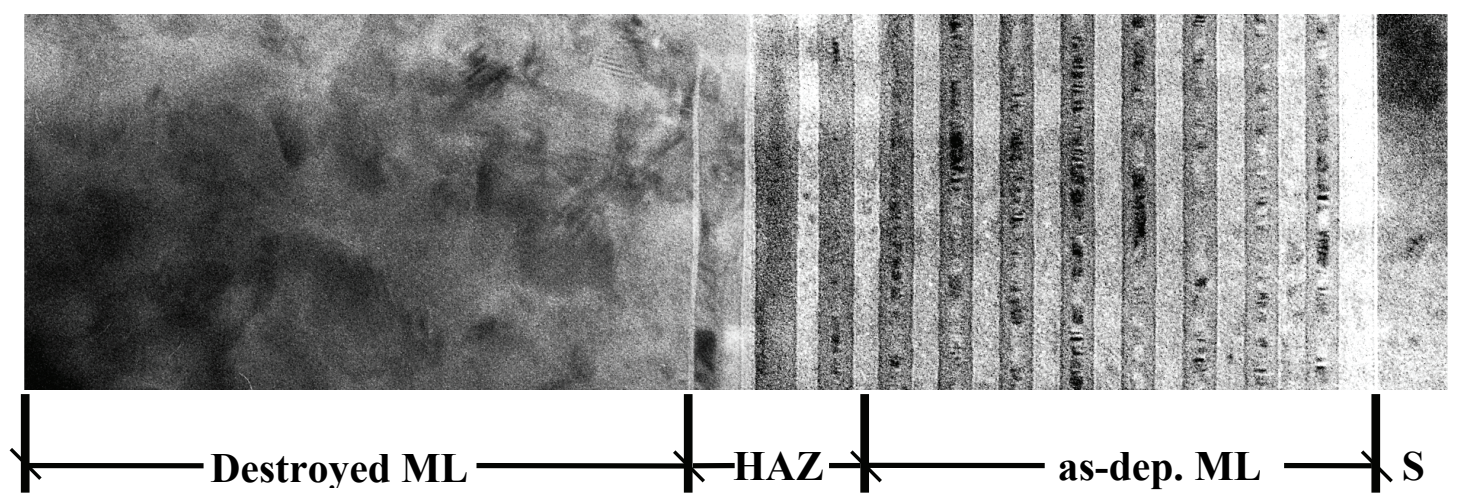

Fig. 2. Cross-sectional TEM image of $\mathrm{Sc} / \mathrm{Si} / 33 \mathrm{ML}$ after laser irradiation. Laser shot was from the left. The molten part of the ML, heat-affected zone (HAZ) and virgin part of ML are observed. Substrate (S) is from the right.

Common features of the melting for all multilayers are morphological changes of the surface and superficial cracking. ${ }^{49}$ The size of cells in the crack network grows with the fluence value. This fact we ascribe to an increase of the melt penetration.

Evaporation and ablation at higher fluences are accompanied by formation of micro-capillaries (black points in Fig. 3b), craters, small solidified drops inside and outside the laser imprint and appearance of a "crown" at the rim. ${ }^{34,49}$ The crown can arise by two reasons. If small fraction of irradiated area is ablated then hydrodynamic pressure within the thermally expanding melt presses out of the liquid in a radial direction. ${ }^{52}$ When the most of irradiated area is evaporated then surface tension force is added to roll up the liquid rim. The latter is confirmed by the chain of small solidified drops (Fig. 3a) left at the border of the solidified liquid after its setback.

As we have shown in this work and before ${ }^{34}$ the damage of Sc/Si MLs by 1.2-ns laser pulses has a thermal character, so application of barrier layers at interfaces will substantially hinder silicide-formation processes running at elevated temperatures. Thus silicide formation in Sc/Si MLs accompanied by period shrinkage goes intensively at $\sim 470 \mathrm{~K}$. ${ }^{39,47,53}$ At the same time period shortening becomes noticeable in $\mathrm{Sc} / \mathrm{W} / \mathrm{Si} / \mathrm{W}$ MXM with subnanometer $\mathrm{W}$-layers only after $\sim 470 \mathrm{~K}^{38,47,53}$ Other materials, such as $\mathrm{Cr}{ }^{54-55}$ and $\mathrm{B}_{4} \mathrm{C}{ }^{56}$, were also used to stabilize Sc-Si interfaces. They demonstrated an ability to work as diffusion barriers. Using barrier layers it is possible to increase thermal stability of $\mathrm{Sc} / \mathrm{Si} \mathrm{MXMs}$ at least by 100-150 degrees. We expect similar effects in radiation stability.

We also observed a periodic surface ripple formation in the form of peaks and valleys within the region around the laser imprint in the $\mathrm{Sc} / \mathrm{Si} / 47$ sample. At relatively small fluences $\left(\sim 1 \mathrm{~J} / \mathrm{cm}^{2}\right.$ and less) this relief appears occasionally at some regions (Fig. 4a) or concentrates near the laser imprint. At relatively large fluences $\left(\sim 1 \mathrm{~J} / \mathrm{cm}^{2}\right.$ and more) it covers the area of several laser imprint diameters (Fig. 4b) and has an appearance of concentric circles around the irradiated region. It is also seen in Fig. 4b that cracks transverse not only irradiated region but also all the region of periodic relief radially. The multilayer coating with the ripples is relatively easy separated from the substrate in the form of elongated leaves. The period value ranges from 1.7 to $2.3 \mu \mathrm{m}$ in dependence on the fluence but without any apparent strict correlation. At a particular fluence the periodicity is almost fixed. For example, it amounts $2.2 \pm 0.1 \mu \mathrm{m}$ along the direction shown in Fig. $4 \mathrm{~b}$ by an arrow. The height of peaks with respect to valleys is within $\sim 0.1 \mu \mathrm{m}$ that is approximately compared to the difference in multilayer thicknesses after interlayer reactions to form $\mathrm{ScSi}$ and $\mathrm{Sc}_{3} \mathrm{Si}_{5}$. We observed up to 200 periods at the multilayer surface within $4.5 \mathrm{~mm}$ (Fig. $4 \mathrm{c}$ ) at laser imprint diameter of $\sim 75 \mu \mathrm{m}$.

One of the peculiarities of the $\mathrm{Sc} / \mathrm{Si} / 47$ sample, which in our opinion should be necessarily present, is residual stress. It is well known that the stressed state is characteristic for Si-based multilayers. ${ }^{57}$ The source of the compressive stress is the $\mathrm{Si}$ layers. The stress value grows as the layer number increases ${ }^{58}$ and can reach such a magnitude that the ML destroys the substrate. ${ }^{59}$ Large number of periods should also result in the development of a high level of compressive residual stress in the $\mathrm{Sc} / \mathrm{Si} / 47$ multilayer. The stress facilitates the detachment of the multilayer from the substrate after the laser shot. 


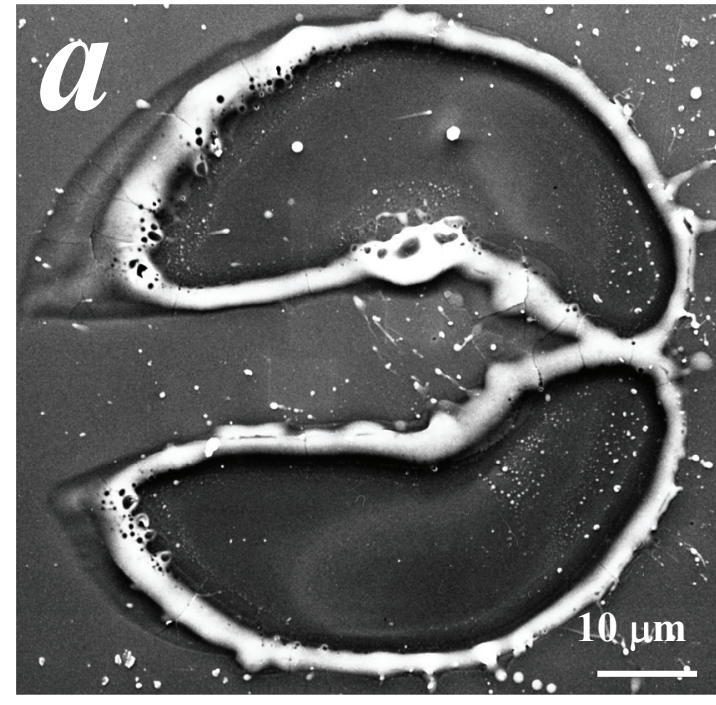

$1.4 \mathrm{~J} / \mathrm{cm}^{2}$

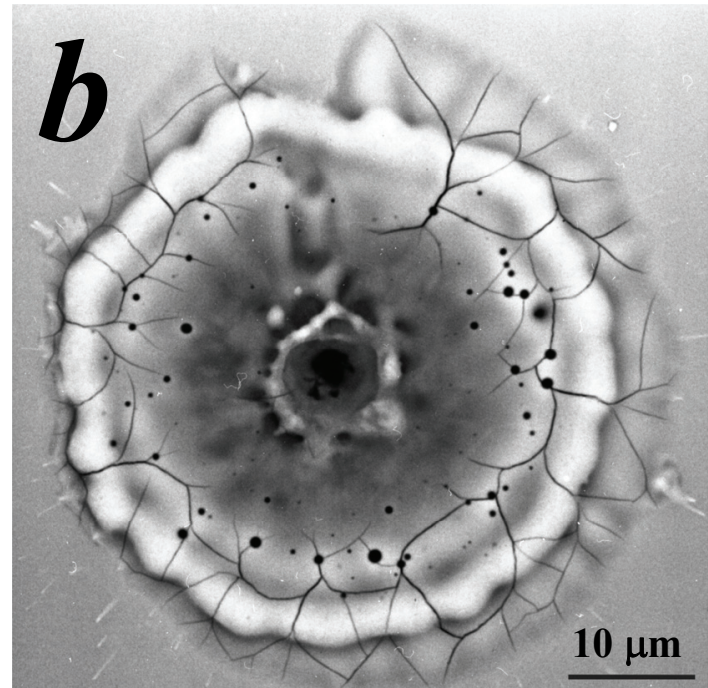

$1.3 \mathrm{~J} / \mathrm{cm}^{2}$

Fig. 3. SEM images of $\mathrm{Sc} / \mathrm{Si} / 10 \mathrm{MXM}(a)$ and $\mathrm{Sc} / \mathrm{Si} / 33 \mathrm{MXM}(b)$ after laser irradiation with fluences of $\sim 1.4$ and $\sim 1.3$ $\mathrm{J} / \mathrm{cm}^{2}$, respectively.

Development of ripples at the surface of metals, semiconductors and dielectrics has been observed after laser irradiation in the range from UV to IR. ${ }^{60-65}$ Periodic relief in this case was formed within the irradiated region sometimes after multiple $(2-10,000)$ pulses. ${ }^{63,65}$ Various mechanisms of ripple formation were proposed the including: a) interference between incidence beam and the beam scattered by surface irregularity defining the ablation rates; ${ }^{60,63,64}$ b) solidification of a standing acoustic wave; ${ }^{60,62,65} \mathrm{c}$ ) relaxation of surface instabilities; ${ }^{65}$ d) Boson condensation, based on electronic excitation $^{61}$ etc. Typical period values obtained in these experiments are (0.13-13.0) $\times \lambda(\lambda$ - laser wavelength).

It has also been reported ${ }^{66}$ about a periodical ripple formation in multilayer nanofoils. Ripples ere experimentally observed in free-standing $\mathrm{Zr} / \mathrm{Al} /(\mathrm{CuNi}) \mathrm{ML}$ nanofoils with $\mathrm{ML}$ period of $\sim 55 \mathrm{~nm}$. After initiating and completing the reaction in nanofoils, the sample surface had an appearance of concentric periodic ripples with a center in the point of initiation. Ripple periodicity was in the range of 8-14 $\mu \mathrm{m}$. An oscillating character of chemical reaction in nanofoils that can result in ripple formation is theoretically predicted in ref. ${ }^{67}$

In our case the periodicity makes $(30-50) \times \lambda(\lambda=46.9 \mathrm{~nm})$, periodic ripples appear outside the laser-irradiated area, and ripples are formed after a single laser shot. Therefore the proposed mechanisms of ripple formation in the samples irradiated by UV-IR lasers don't quite apply to our samples. In our opinion the most acceptable mechanism of periodic ripple formation is a chemical reaction of $\mathrm{Sc}$ and $\mathrm{Si}$. Although up to now we have no direct evidence of silicide formation in the ripple region, we don't see any acceptable reason for the volume variation except for silicide formation. We can expect the following evolution of events in multilayer samples after laser irradiation. On melting of the sample surface by the laser shot, thermoelastic expansion of the melt creates transverse ultrasonic waves. ${ }^{62,68}$ These waves and residual stress result in detachment of the multilayer from the substrate. The molten region initiates the chemical reaction, which proceeds in the already detached multilayer. So appearance of the periodic relief is the result of oscillation in the chemical reaction consisting in different stages of silicide formation.

Heat release during the reaction in MLs may be the main reason of a relatively low damage threshold compared to bulk material. We measured a damage threshold for Si wafers ${ }^{34}$ to be $0.7 \mathrm{~J} / \mathrm{cm}^{2}$, that is almost an order of magnitude higher than that for a ML $\left(0.08 \mathrm{~J} / \mathrm{cm}^{2}\right)$. It should be noted that damage threshold of $0.13 \mathrm{~J} / \mathrm{cm}^{2}$ was reported for a crystalline $\mathrm{Si}$ sample irradiated by a 14-ns $193-n m$ excimer laser beam. ${ }^{60}$ The latter value is closer to the observed ML threshold. A damage mechanism for materials should not be considerably different in the nanosecond regime of laser irradiation. ${ }^{69}$ 


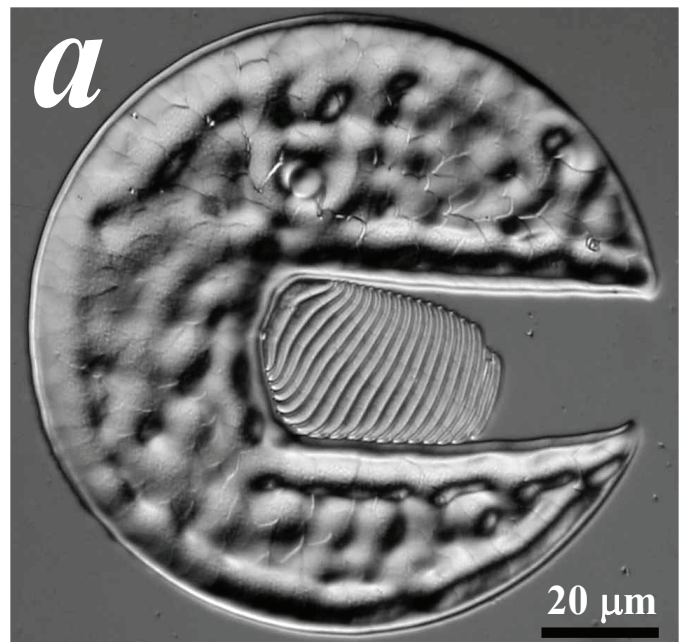

$0.5 \mathrm{~J} / \mathrm{cm}^{2}$

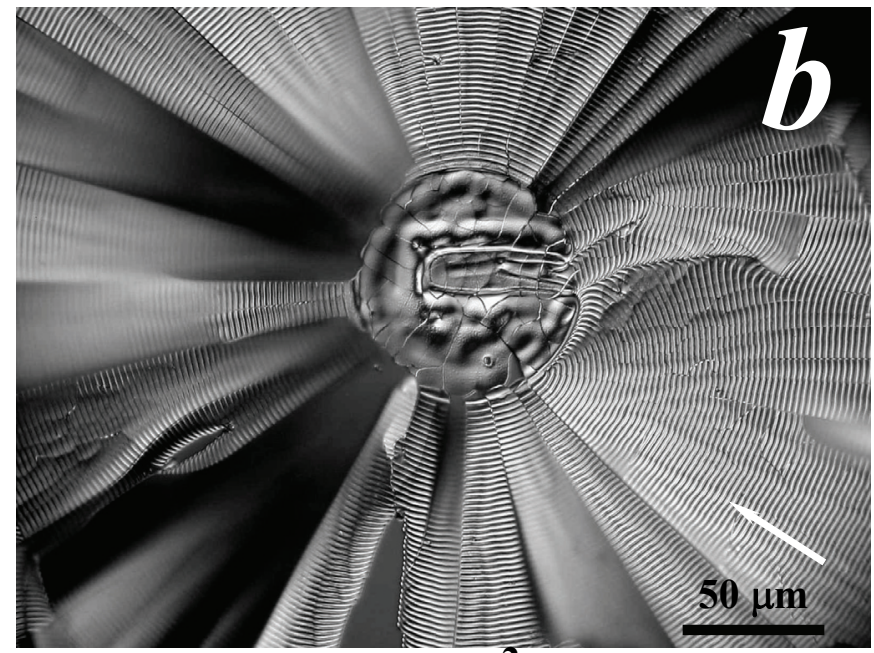

$0.9 \mathrm{~J} / \mathrm{cm}^{2}$

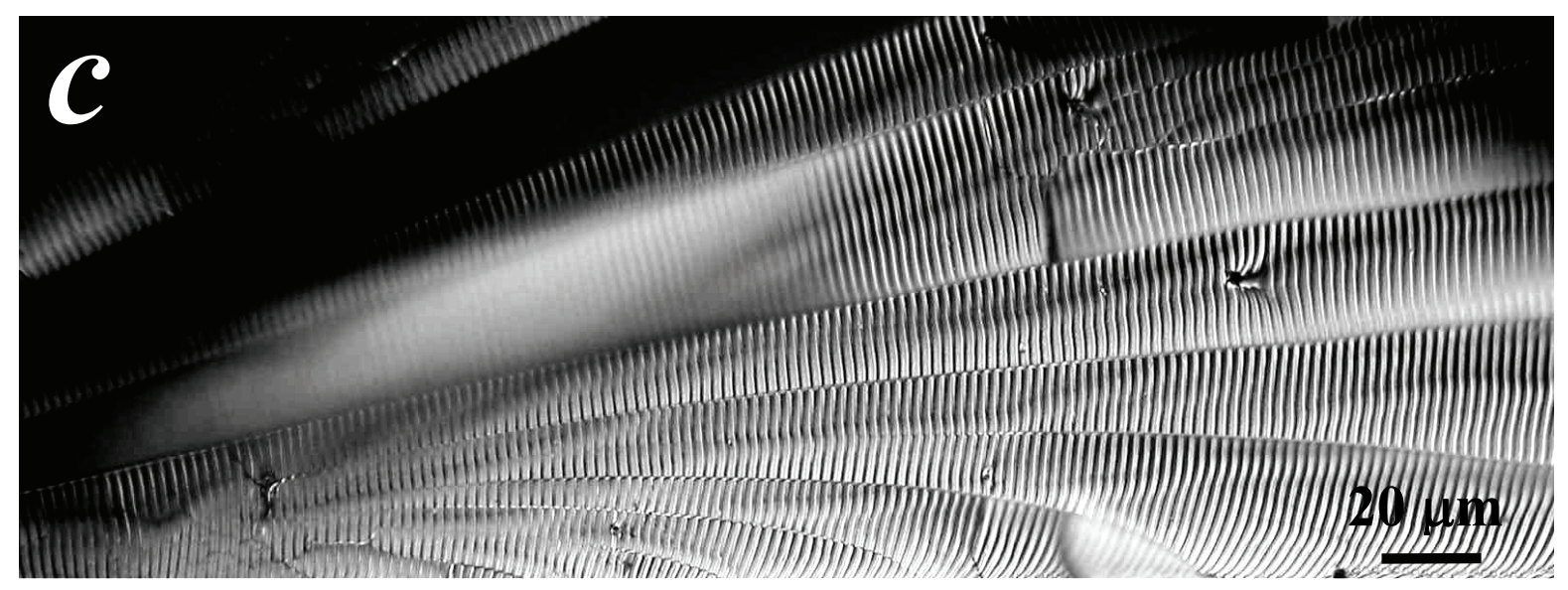

Fig. 4. Optical surface images of Sc/Si/47 MXM after laser irradiation with fluences of $\sim 0.5 \mathrm{~J} / \mathrm{cm}^{2}(a)$ and $\sim 0.9 \mathrm{~J} / \mathrm{cm}^{2}(b, c)$.

We see the main difference of results in optical absorption $\left(\sim 0.018\right.$ for $46.9 \mathrm{~nm}$ and $\sim 2.8$ for $193 \mathrm{~nm}^{70}$ ). Hence we can expect different volumes of heat release and different damage fluences respectively.

\section{CONCLUSIONS}

Features concerning the interaction of pulsed $(\sim 1.2 \mathrm{~ns})$ capillary-discharge $\mathrm{x}$-ray laser $(\lambda=46.9 \mathrm{~nm})$ beams with $\mathrm{Sc} / \mathrm{Si}$ multilayers having different period number $(\mathrm{Sc} / \mathrm{Si} / 1.5, \mathrm{Sc} / \mathrm{Si} / 10, \mathrm{Sc} / \mathrm{Si} / 33$ and $\mathrm{Sc} / \mathrm{Si} / 47)$ during single-shot irradiation with fluences exceeding melting threshold $\left(>0.08 \mathrm{~J} / \mathrm{cm}^{2}\right)$ were studied. It was shown that the damage mechanism has a thermal nature that is confirmed by comparison with results of $\mathrm{Sc} / \mathrm{Si}$ multilayer isothermal annealings.

The damage threshold decreases as conditions for heat removal deteriorate: ML body ( $\mathrm{Sc} / \mathrm{Si} / 47$ and $\mathrm{Sc} / \mathrm{Si} / 33$ ), glass substrate $(\mathrm{Sc} / \mathrm{Si} / 10)$ and free-standing $\mathrm{ML}(\mathrm{Sc} / \mathrm{Si} / 1.5)$.

Solid-state reaction of $\mathrm{Sc}_{3} \mathrm{Si}_{5}$ silicide formation was found to occur under laser irradiation in free-standing $\mathrm{Si} / \mathrm{Sc} / \mathrm{Si}$ threelayers $(\mathrm{Sc} / \mathrm{Si} / 1.5)$ at sub-melting thresholds.

Heat release during the exothermic reaction of silicide formation enhances many-fold the laser heat effects consisting in growth of the molten volume or early-stage ablation. 
The appearance of periodic surface ripples in $\mathrm{Sc} / \mathrm{Si} / 47$ multilayers around the laser imprint is observed. The rippled region grows as fluence increases and can exceed the imprint dimension dozens of times. Ripple periodicity is in the range of 1.7-2.3 $\mu \mathrm{m}$ and doesn't correlate with fluence value. Ripple formation may be closely associated with an oscillating character of silicide formation reaction proceeding in the ML, being separated from the substrate at the moment of laser shot due to an induced ultrasonic wave.

\section{ACKNOWLEDGEMENTS}

The authors are grateful to W. McKinney for extremely useful discussions. This work was supported by the U. S. Department of Energy under contract number DE-AC02-05CH11231.

\section{REFERENCES}

1. http://henke.lbl.gov/cgi-bin/mldata.pl

2. D.L. Windt, J.F. Seely, D. Kjornrattanawanich, Y.A. Uspenskii, "Terbium-based extreme ultraviolet multilayers," Opt. Lett. 30(23), 3186-31888 (2005).

3. I. Yoshikawa, A. Yamazaki, T. Murachi, S. Kameda, H. Sagawa, S. Okano, T. Okada and M. Nakamura, "Development of an extreme ultraviolet imaging spectrometer for the BepiColombo mission," Advances in Space Res. 33(12), 2195-2199 (2004).

4. L. Golub, J. Bookbinder, E. DeLuca, M. Karovska, and H. Warren, C. J. Schrijver, R. Shine, T. Tarbell, A. Title, and J. Wolfson, B. Handy and C. Kankelborg, "A new view of the solar corona from the transition region and coronal explorer (TRACE)," Physics of Plasmas 6(5), 2205-2216 (1999).

5. C. W. Gwyn, "Extreme ultraviolet lithography," J. Vac. Sci. Technol. B 16(6), 3142-3149 (1998).

6. Richard H. Stulen and Donald W. Sweeney, "Extreme Ultraviolet Lithography," IEEE Journal of Quantum Electronics, 35(5), 694-699 (1999).

7. T. Chassé, H. Neumann, B. Ocker, M. Scherer, W. Frank, F. Frost, D. Hirsch, A. Schindler, G. Wagner, M. Lorenz, G. Otto, M. Zeuner, B. Rauschenbach, "Mo/Si multilayers for EUV lithography by ion beam sputter deposition," Vacuum 71, 407-415 (2003).

8. A. Nefedov, H. Zabel and F. Schäfers, "Sputtered V/A12O3 multilayer X-ray mirrors for the water window," Nucl. Instrum. Meth. Phys. Res. Sec. A: Accelerators, Spectrometers, Detectors and Associated Equipment, 467-468 (1), $345-$ 348 (2001).

9. H. Takenaka, H. Ito, K. Nagai, Y. Muramatsu, E. Gullikson and R. C. C. Perera, "Soft X-ray reflectivity and structure evaluation of Ni/C/Ti/C multilayer X-ray mirrors for water-window region," Nucl. Instrum. Meth. Phys. Res. Sec. A: Accelerators, Spectrometers, Detectors and Associated Equipment, 467-468(1), 341-344 (2001).

10. F. Eriksson, G.A. Johansson, H.M. Hertz, E.M. Gullikson, U. Kreissig, J. Birch, "14.5\% near-normal incidence reflectance of Cr/Sc x-ray multilayer mirrors for the water window," Opt Lett. 28(24), 2494-2496 (2003).

11. H. Stollberg, S. Yulin, P. A. C. Takman and H. M. Hertz, "High-reflectivity Cr/Sc multilayer condenser for compact soft x-ray microscopy," Rev. Sci. Instrum. 77, 123101 (2006).

12. I.A. Artioukov, O.V. Chefonov, O.N. Gilev, A.V. Lipin, V.I. Ostashev, A.V. Potapov, V.A. Pronin, I.L. Svyatov, D.A. Vikhlyaev, and A.V. Vinogradov, "Experimental research of stability of thin films on the basis of depleted uranium as reflecting coating for wavelength of $4.5 \mathrm{~nm}$," Nucl. Instrum. Meth. Phys. Res. Sec. A: Accelerators, Spectrometers, Detectors and Associated Equipment, 575(1-2), 248-250 (2007).

13. Igor A. Artyukov, Yegor A. Bugayev, Oleksandr Yu. Devizenko, Ruslan M. Feschenko, Yuri S. Kasyanov, Valeri V. Kondratenko, Svetlana A. Romanova, Sergei V. Saveliev, Franz Schäfers, Torsten Feigl, Yuri A. Uspenski, Alexander V. Vinogradov, "Carbon window soft x-ray imaging using multilayer optics," Proc. of SPIE "Soft X-Ray Lasers and Applications VI”, 5919, OE1-OE10 (2005).

14. S. S. Andreev, H. -Ch. Mertins, Yu. Ya. Platonov, N. N. Salashchenko, F. Schaefers, E. A. Shamov and L. A. Shmaenok, "Multilayer dispersion optics for X-ray radiation," Nucl. Instrum. Meth. Phys. Res. Sec. A: Accelerators, Spectrometers, Detectors and Associated Equipment, 448(1-2), 133-141 (2000).

15. D. A. Fischer and S. Sambasivan, A. Kuperman, "Focusing multilayer mirror detection system for carbon K edge soft x-ray absorption spectroscopy (invited)," Rev. Sci. Instrum. 73(3), 1469-1475 (2002). 
16. Ning Gao and Zewu Chen, Qifan Xiao, "A microbeam wavelength-dispersive X-ray fluorescence system and its application for thin-film analysis," Rev. Sci. Instrum. 76, 123104 (2005).

17. V. Ayvazyan, N. Baboi et al., "Generation of GW radiation pulses from a VUV free-electron laser operating in the femtosecond regime," Phys. Rev. Lett. 88, 104802 (2002).

18. W. Brefeld, B. Faatz, J. Feldhaus, M. Körfer, J. Krzywinski, T. Möller, J. Pflueger, J. Rossbach, E. L. Saldin, E. A. Schneidmiller, S. Schreiber and M. V. Yurkov, "Generation of high power femtosecond pulses by a sideband-seeded Xray FEL," Nucl. Instrum. Meth. Phys. Res. Sec. A: Accelerators, Spectrometers, Detectors and Associated Equipment, 483(1-2), 62-69 (2002).

19. R. Follath, "Design of FEL-beamlines for short pulse, high resolution and high power Density," AIP Conference Proceedings (Synchrotron Radiation Instrumentation: Ninth International Conference on Synchrotron Radiation Instrumentation.), 879, 513-518 (2007).

20. Andreas K Freund, “Third-generation synchrotron radiation X-ray optics,” Structure, 4(2), 121-125 (1996).

21. A. Ritucci, G. Tomassetti, A. Reale, and L. Reale, F. Flora and L. Mezi, "Measurements of energy fluctuations of a saturated $46.9 \mathrm{~nm}$ Ar laser produced in Z-pinch capillary discharges," Appl. Phys. Lett. 86, 101106 (2005).

22. J. J. Rocca, B. M. Luther, S. Heinbuch, M. A. Larotonda, Y. Wang, D. Alessi, M. Berrill, M. C. Marconi, C. S. Menoni and V. N. Shlyaptsev, "High repetition rate table-top soft X-ray lasers in capillary discharges and laser-created plasmas," AIP Conference Proceedings (6th International Conference on Dense Z-Pinches) 808, 241-246 (2006).

23. B.J. MacGowan, S. Mrowka, T.W. Barbee, L.B. Da Silva, D.C. Eder, J.A. Koch, L.S. Pan, J.A. Turner, J.H. Underwood and P.E. Young, "Investigation of demage to multilayer optics in X-ray laser cavities: W/C, WRe/C, WC/C, stainless-steel/C, and $\mathrm{Cr}_{3} \mathrm{C}_{2} / \mathrm{C}$ mirrors," J. X-ray Sci. Technol. 3, 231-282 (1993).

24. Vaschenko G, Etxarri AG, Menoni CS, Rocca JJ, Hemberg O, Bloom S, Chao W, Anderson EH, Attwood DT, Lu Y, Parkinson B., "Nanometer-scale ablation with a table-top soft x-ray laser," Opt. Lett. 31(24), 3615-3617 (2006).

25. C.H. Moreno, M.C. Marconi, K. Kanizay, J.J. Rocca, Yu.A. Uspenskii, A.V. Vinogradov, Yu.P. Pershyn, “Soft-xray laser interferometry of a pinch discharge using a tabletop laser," Phys. Rev. E, 60(1), 911-917 (1999).

26. B.R. Benware, M. Seminario, A.I. Lecher, J.J. Rocca, Yu.A. Uspenskii, A.V. Vinogradov, V.V. Kondratenko, Yu.P. Pershyn, B. Bach, "Generation and application of a high-average-power polarized, soft-x-ray laser beam," J. Opt. Soc. Am. B, 18(7), 1041-1045 (2001).

27. I.A. Artioukov, B.R. Benware, R.M. Fechtchenko, J.J. Rocca, M. Seminario, A.V. Vinogradov and M. Yamamoto, "The prospects of reflectometry and ellipsometry with Colorado State University tabletop XUV laser," J. Phys. IV France [ $7^{\text {th }}$ International Conference, on X-ray Lasers (“X-ray Lasers 2000”), Saint Malo, France, June 19-23, 2000], 11, Pr2-451-457 (2001).

28. J.J. Rocca, M. Seminario, M. Frati, B.R. Benware, H.L. Mancini, J. Filevich, M.C. Marconi, K. Kanizay, A. Ozols, I.A. Artioukov, A.V. Vinogradov, Yu.A. Uspenskii, G.G. Tomasel, and V.N. Shlyaptsev, "Applications of high repetition rate tabletop soft X-ray lasers become a reality in several fields," J. Phys. IV France [7 ${ }^{\text {th }}$ International Conference, on X-ray Lasers (“X-ray Lasers 2000”), Saint Malo, France, June 19-23, 2000], 11, Pr2-459-468 (2001).

29. John F. Seely, Yu.A. Uspenskii, Yu.P. Pershyn, V.V. Kondratenko and V.V. Vinogradov, "Skylab 3600 groove/mm replica grating with a scandium-silicon multilayer coating and high normal incidence efficiency at 38-nm wavelength," Appl. Opt. 41(10), 1846-1851 (2002).

30. I.A. Artioukov, B.R. Benware, A.V. Vinogradov, Yu. S. Kas’yanov, V.V. Kondratenko, C.D. Macchietto, A. Ozols, J.J. Rocca and J.L.A. Chilla, "Focusing the beam of a compact, repetitively pulsed x-ray laser to study the interaction of radiation with metallic targets and x-ray reflectometry," Quantum Electronics, 30(4), 328-332 (2000).

31. Fernando Brizuela, Georgiy Vaschenko, Courtney Brewer, Michael Grisham, Carmen S. Menoni, Hector Mancini, Mario C. Marconi, Jorge J. Rocca, Weilun Chao, J. Alexander Liddle, Erik H. Anderson, David T. Attwood, Alexander V. Vinogradov, Igor A. Artioukov, Yuriy P. Pershyn and Valeriy V. Kondratenko, "Nanometer-scale imaging with compact soft x-ray lasers," Proc. of SPIE: Soft X-Ray Lasers and Applications VI, 5919, ON1-ON7 (2005).

32. F. Brizuela, G. Vaschenko, C. Brewer, M. Grisham, C. S. Menoni, M. C. Marconi, and J. J. Rocca, W. Chao, J. A. Liddle, E. H. Anderson, and D. T. Attwood, A. V. Vinogradov and I. A. Artioukov, Y. P. Pershyn and V. V. Kondratenko, "Reflection mode imaging with nanoscale resolution using a compact extreme ultraviolet laser," Optics Express, 13(11), 3983-3988 (2005).

33. Vaschenko G, Brizuela F, Brewer C, Grisham M, Mancini H, Menoni CS, Marconi MC, Rocca JJ, Chao W, Liddle JA, Anderson EH, Attwood DT, Vinogradov AV, Artioukov IA, Pershyn YP, Kondratenko VV., "Nanoimaging with a compact extreme-ultraviolet laser," Opt. Lett. 30(16), 2095-2097 (2005). 
34. M. Grisham, G. Vaschenko, C. S. Menoni, and J. J. Rocca, Yu. P. Pershyn, E. N. Zubarev, D. L. Voronov, V. A. Sevryukova, and V. V. Kondratenko, A. V. Vinogradov and I. A. Artioukov, "Damage to extreme-ultraviolet Sc-Si multilayer mirrors exposed to intense 46.9-nm laser pulses," Opt. Lett. 29(6) , 620-622 (2004).

35. M. E. Grisham, G. Vaschenko, C. S. Menoni, L. Juha, M. Bittner, Yu. P. Pershyn, V. V. Kondratenko, E. N. Zubarev, A. V. Vinogradov, I. A. Artioukov and J. J. Rocca, "Materials modification with intense extreme ultraviolet pulses from a compact laser," Ch. 21 in Laser Ablation and its Applications, ed. Claude Phipps, Springer, 129, 529-548 (2007).

36. J. C. Bravman and R. Sinclair, "The preparation of cross-section specimens for transmission electron microscopy," J. Electron. Microsc. Tech. 1, 53-61 (1984).

37. E. N. Zubarev, V. V. Kondratenko, O. V. Poltseva, V. A. Sevryukova, A. I. Fedorenko, S. A. Yulin, "Interface mixed zones in Mo-Si superlattices," Metallofizika i noveishie tehnologii, 19, 56-63 (1997) (in Russian).

38. D. L. Voronov, E. N. Zubarev, V. V. Kondratenko, A. V. Penkov, Yu. P. Pershyn, A. I. Fedorenko, "Layer interaction in multilayer Sc/Si and Sc/W/Si/W coatings," Functional Materials. 6(5), 856-859 (1999).

39. D.L. Voronov, E.N. Zubarev, V.V. Kondratenko, A.V. Penkov, Yu.P. Pershyn, "Peculiarities of silicide formation in Sc/Si multilayer system," Poverhhnost. Rentgenovskie, sinhrotronnye i neitronnye issledovaniya, (2), 75-79 (2002) (in Russian).

40. To be published

41. L. Hultman, A. Robertsson, and H. T. G. Hentzell, "Crystallization of amorphous silicon during thin-film gold reaction," J. Appl. Phys. 62(9), 3647-3655 (1987).

42. Ming Wu and Sigurd Wagner, "Amorphous silicon crystallization and polysilicon thin film transistors on $\mathrm{SiO} 2$ passivated steel foil substrates," Appl. Surf. Sci. 175-176, 753-758 (2001).

43. Ali Khakifirooz, Saber Haji and S. Shamsoddin Mohajerzadeh, "UV-assisted nickel-induced crystallization of amorphous silicon," Thin Solid Films, 383(1-2), 241-243 (2001).

44. Sung Bo Lee and Duck-Kyun Choi, "Transmission electron microscopy observations of Cu-induced directional crystallization of amorphous silicon," J. Appl. Phys. 98, 114911 (2005).

45. G.J. Qi, S. Zhang, T.T. Tang, J.F. Li, X.W. Sun and X.T. Zeng, "Experimental study of aluminum-induced crystallization of amorphous silicon thin films," Surface and Coatings Technology, 198(1-3), 300-303 (2005).

46. A.I. Fedorenko, A.S. Garbuz, V.V. Kondratenko, Yu.P. Pershyn, V.E. Puksha, O.V. Poltseva, S.A. Yulin and E.N. Zubarev, "Thermally induced structural and phase transformations of Mo-Si and MoSi2-Si X-ray multilayer mirrors," Functional materials, 1(2), 33-44 (1994).

47. D. L. Voronov, Ph.D. thesis, V.N. Karazin Kharkov National University, 2002 (in Russian).

48. Yu. M. Golutvin, E. G. Maslennikova, and L. G. Titov, "Enthalpy of silicide formation in Sc-Si system," Izv. Akad. Nauk SSSR, Met. (6), 47-55 (1984) (in Russian).

49. Yu.P. Pershyn, D.L. Voronov, E.N. Zubarev, V.A. Sevryukova, V.V. Kondratenko, G. Vaschenko, M. Grisham, C. S. Menoni, J. J. Rocca, A.V. Vinogradov, I.A. Artyukov, Yu.A. Uspenskii, “Analysis of 46.9-nm pulsed laser radiation aftereffects in Sc/Si multilayer X-ray mirrors," X-ray Lasers 2006 (Eds. P.V. Nickles, K.A. Janulewicz), Springer Proceedings in Physics, Springer, Dordrecht, The Netherlands, 115, 563-570 (2007).

50. Handbook of Physical and chemical properties of oxides, ed. G.V. Samsonov, Moscow, Metallurgiya, 1978 (in Russian).

51. Handbook on Properties of elements. Pt. 1. Physical properties, ed. G.V. Samsonov, Moscow, Metallugiya, 1976 (in Russian).

52. C. Körner, R. Mayerhofer, M. Hartmann, H.W. Bergmann, "Physical and material aspects in using visible laser pulses of nanosecond duration for ablation,” App. Phys. A 63, 123-131 (1996).

53. Dmitry L. Voronov, Evgeniy N. Zubarev, Alexey V. Penkov, Yuriy P. Pershyn, Alexander G. Ponomarenko, Igor A. Artioukov, Alexander V. Vinogradov, Yuriy A. Uspenskii and John F. Seely, "Thermoresistive multilayer mirrors antidiffusion barriers for work at the wavelengths 40-50 nm," AIP Conference Proceedings «X-Ray Lasers 2002», Aspen, Colorado, 27-31 May 2002, 641, 575-582 (2002).

54. Sergiy A. Yulin, Franz Schaefers, Torsten Feigl and Norbert Kaiser, "Enhanced reflectivity and stability of Sc/Si multilayers," SPIE Proc. 5193, 155-163 (2004).

55. D.L. Voronov, A.G. Ponomarenko, E.N. Zubarev, V.V. Kondratenko, A.V. Penkov, V.A. Sevryukova, I.A. Kopylets, A.V. Vinogradov, I.A. Artiuokov, Yu.A. Uspenskii, Yu.S. Kasyanov, J.J. Rocca, "Fabrication and characterization of Sc/Cr/Si multilayer mirrors for Schwarzschild optics for 46.9-nm compact capillary-discharge laser," X-ray Lasers 2006 (Eds. P.V. Nickles, K.A. Janulewicz), Springer Proceedings in Physics, Springer, Dordrecht, The Netherlands, 115, (2007). 
56. A.F. Jankowski, C.K. Saw, C.C. Walton, J.P. Hayes, J. Nilsen, "Boron-carbide barrier layers in scandium-silicon multilayers," Thin Solid Films, 469-470, 372-379 (2004).

57. David L. Windt, "Stress, microstructure, and stability of Mo/Si, W/Si, and Mo/C multilayer films," J. Vac. Sci. Technol. A, 18(3), 980-991 (2000).

58. J. M. Freitag and B. M. Clemens, "Stress evolution in Mo/Si multilayers for high-reflectivity extreme ultraviolet mirrors," Appl. Phys. Lett. 73(1), 43-45 (1998).

59. V.V. Kondratenko, "Periodic multilayers $\mathrm{MoSi}_{2} / \mathrm{Si}$ with a large number of periods," Cryst. Res. Technol. 33(1), 7178 (1998).

60. G. Gorodetsky, Jerzy Kanicki, T. Kazyaka, and R.L. Melcher, "Far UV pulsed laser melting of silicon," Appl. Phys. Lett. 46(6), 547-549 (1985).

61. Amit Pratap Singh, Avinashi Kapoor, K. N. Tripathi, G. Ravindra Kumar, "Laser damage of silicon sutface using ultra-short laser pulses," Optics \& Laser Technol. 34, 34-43 (2002).

62. G.H. Lv, B.Y. Man, Y.H. Zhang, A.H. Liu, Q.G. Zhang, "Analysis of surface damage and plasma properties of pulsed laser ablation of GaAs," Optik, 115(8), 347-350 (2004).

63. J. Bonze, M. Munz, H. Sturm, "Structure formation on the surface of indium phosphide irradiated by femtosecond laser pulses,” J. Appl. Phys., 97, 013538 (2005).

64. Jincheng Wang and Chunlei Guo, "Formation of extraordinarily uniform periodic structures on metals induced by femtosecond laser pulses," J. Appl. Phys. 100, 023511 (2006).

65. Florenta Costache, Matthias Henyk, Jürgen Reif, "Modification of dielectric surfaces with ultra-short laser pulses," Appl. Surf. Sci. 186, 352-357 (2002).

66. J.C. Trenkle, J. Wang, T.P. Weihs and T.C. Hufnagel, "Microstructural study of an oscillatory formation reaction in nanostructured reactive multilayer foils," Appl. Phys. Lett. 87, 153108 (2005).

67. S. Jayaraman, O.M. Knio, A.B. Mann, and T.P. Weihs, "Numerical predictions of oscillatory combustion in reactive multilayers," J. Appl. Phys. 86(2), 800-809 (1999).

68. T. Efthimiopoulos, E. Kritsotakis, H. Kiagias, C. Savvakis and Y. Bertachas, "Laser ablation rate of materials using the generated acoustic waves," J. Phys. D: Appl. Phys. 31, 2648-2652 (1998).

69. B.N. Chichkov, C. Momma, S. Nolte, F. von Alvensleben, A. Tünnermann, "Femtosecond, picosecond and nanosecond ablation of solids," Appl. Phys. A, 63, 109-115 (1996).

70. Handbook of Optical Constants of Solids II, ed. E.D. Palik, Academic Press, New York, 1991. 